\title{
Cotton-hydrogel composite for improved wound healing: Antimicrobial activity and anti-inflammatory evaluation-Part 2
}

\author{
Eva Pinho ${ }^{1}$ (I) । Ricardo C. Calhelha ${ }^{2}$ (1) । Isabel C.F.R. Ferreira ${ }^{2}$ (D) | Graça Soares ${ }^{1}$ (i)
}

${ }^{1}$ Centre for Textile Science and Technology (2C2T), University of Minho, Campus Azurém, Guimarães, Portugal

${ }^{2}$ Centro de Investigação de Montanha (CIMO), Instituto Politécnico de Bragança, Campus de Santa Apolónia, Bragança, Portugal

Correspondence

Eva Pinho, Centre for Textile Science and Technology (2C2T), University of Minho, Campus Azurém, Guimarães 4800-058,

Portugal.

Email: eva.pinho@2c2t.uminho.pt

Funding information

COMPETE 2020-Programa Operacional

Competitividade e Internacionalização (POCI), Grant/Award Number: POCI-01-0145FEDER-007136; NORTE 2020, Grant/Award Number: TSSIPRO-NORTE-01-0145-FEDER000015; Portuguese Foundation for Science and Technology, Grant/Award Number: UID/ CTM/00264/2013
Infection is one of the major risk factors for the development of chronic wounds. Antimicrobial wound dressing has been pointed out as a viable option for the prevention and treatment of wound infections. Thus, we developed a composite material based on cotton textile substrates functionalized with cyclodextrin-hydroxypropyl methyl cellulose-based hydrogel. The composites' ability to encapsulate and release gallic acid (antimicrobial phenolic acid) was evaluated, as well as their mechanical properties and antimicrobial and anti-inflammatory capacity. All composites were able to retain gallic acid in their structure, with similar loading profile. The presence of gallic acid on composites was confirmed by FTIR and TGA. Composites storage moduli was reduced by the presence of gallic acid. The results suggest a straight relation between the swelling ability and gallic acid drug delivery profile. The drug delivery mechanism, of the developed composites, was mainly controlled by Fickian diffusion, based on the experimental data fitting to the Peppas-Sahlin model. Gallic acid antimicrobial and anti-inflammatory properties were transferred to the composite materials. According to the results, the developed composites can be applied on the prevention or treatment of chronic wounds.

\section{KEYWORDS}

anti-inflammatory, antimicrobial, chronic wound, composite wound dressing, gallic acid, infection

\section{1 | INTRODUCTION}

Wound dressings' research has been set by the insights on wound healing process and by patients' demands. Nowadays, the patients have high expectations regarding the wound dressings. They must accelerate cicatrization, with minimal pain and best cosmetic and functional results. ${ }^{1,2}$ This is especially important in the case of chronic or nonhealing wounds. Chronic wounds represent a silent epidemic affecting a large fraction of the world's population. They are a burgeoning cost in the health care system, aggravated by demographic developments. ${ }^{3}$ Chronic wounds can be triggered by repeated ischemia-reperfusion injury, altered cellular and systemic response, tissue hypoxia, or microorganisms. ${ }^{4,5}$ Among these, microorganism colonization and posterior infection are particularly significant, since virtually, all chronic wounds became contaminated, delaying the healing, causing malodorous and exudates. ${ }^{4}$ Thus, the elimination of clinically relevant infections is a prerequisite for efficient wound healing. ${ }^{6}$
The most common treatment for infected chronic wounds is the systemic administration of broad-spectrum antibiotics. ${ }^{7}$ Their indiscriminate use affects skin flora and induce multiresistant strains. ${ }^{8}$ Topical treatment with antimicrobial agents has been pointed out as a good alternative to antibiotic therapy. Topical delivery ensures antimicrobial agent release at the infection site, reducing the concentration need to control the infection and, consequently, the systemic absorption and toxicity. ${ }^{4,9}$

Antimicrobial wound dressings have been often used to protect the wound from new injury, dehydration, and microorganism deposition. $^{2}$ Several materials (textiles, hydrogels, foams, and films) have been developed to deliver antimicrobial agents to infected wounds. ${ }^{10}$ Although, they still show inadequate release profile, characterized by an initial burst that leads to local toxicity owed high antimicrobial concentration, followed by a prolonged release of antimicrobial agent below required concentration, selecting the resistant microorganisms. ${ }^{9}$ 
In a previous work, ${ }^{11}$ our research group optimized the synthesis of a composite wound dressing obtained through the combination of cotton textile substrates and cyclodextrin-hydroxypropyl methyl cellulose-based hydrogel. The developed composite should gather the suitable properties of textiles wound dressing, mechanical stability and biocompatibility, and the hydrogels drug delivery and surface properties. ${ }^{7,11,12}$ In order to complement the previous work, composites' ability to encapsulate and release small antimicrobial molecules was evaluated, as well as their mechanical properties. The composites' antimicrobial and anti-inflammatory activities were also assessed.

\section{2 | MATERIALS AND METHODS}

\section{1 | Materials}

Gallic acid (3,4,5-trihydroxybenzoic acid) was provided by Merck, and $\beta$ cyclodextrin ( $\beta C D, 1135 \mathrm{~g} \mathrm{~mol}^{-1}$ ) and 2-hydroxypropyl- $\beta$-cyclodextrin (HPßCD, $1309 \mathrm{~g} \mathrm{~mol}^{-1}$ ) were acquired from AppliChem. Hydroxypropyl methylcellulose (HPMC) Methocel K4 M (84 $200 \mathrm{~g} \mathrm{~mol}^{-1}$; normal viscosity, $400 \mathrm{mPa}$ s) was purchased from VWR Prolab; 1,4-butanediol diglycidyl ether (BDGE, 50\%-60\% v/v) was obtained from Acros Organics. Purified water, obtained by reverse osmosis (MiliQ, Mikipore, Madrid, Spain) with a resistivity above $18.2 \mathrm{MX} \mathrm{cm}$, was used. RAW264.7 cells were purchased from ECACC (European Colletion of Authenticated Cell Culture, Salisbury, UK), lipopolysaccharide (LPS) from Sigma, and DMEM medium from HyClone. The Griess Reagent System Kit was purchased from Promega and dexamethasone from Sigma. The textile substrates used were as follows: cotton (COT) $100 \%$ tubular mesh with $150 \mathrm{~g} \mathrm{~m}^{-2}$, washed according to ISO 105C01, sterile nonwoven (NW) $100 \%$ cotton with $54 \mathrm{~g} \mathrm{~m}^{-2}$, and sterilized gauze (GZ) $100 \%$ cotton with $24 \mathrm{~g} \mathrm{~m}^{-2}$.

\section{2 | Composites synthesis}

The optimal conditions to synthesize cotton-hydrogel composites were described in a previous work. ${ }^{11}$ The composites used in this work were obtained by one-step cross-linking procedure. A polymeric solution was prepared by dissolving the $C D s\left(0.22 \mathrm{~mol} \mathrm{~L}^{-1}\right.$ of $\beta C D$ or $0.19 \mathrm{~mol} \mathrm{~L}^{-1}$ of HPßCD) and HPMC $\left(5.95 \times 10^{-5} \mathrm{~mol} \mathrm{~L}^{-1}\right)$ in $\mathrm{NaOH}$ ( $5 \mathrm{~mL} \mathrm{0.2M).} \mathrm{Then} \mathrm{they} \mathrm{were} \mathrm{transferred} \mathrm{to} \mathrm{petri} \mathrm{dishes,} \mathrm{and} \mathrm{the}$ cross-linking agent ( $0.54 \mathrm{~mol} \mathrm{~L}^{-1}$ of BDGE) was added. After homogenization, the textile subtracts ( $0.30 \mathrm{~g}$ of $\mathrm{COT}, \mathrm{NW}$, or GZ) were immersed on the solutions. The cross-linking procedure was performed at $50^{\circ} \mathrm{C}$ for 20 hours. To remove the chemical residues, the composites were washed with water (12 h), $\mathrm{HCl}(10 \mathrm{mM})$ for an additional 12 hours, and kept in water for 7 days, at $25 \pm 1^{\circ} \mathrm{C}$. After, they were dried at $40 \pm 1^{\circ} \mathrm{C}$ for 24 hours and stored in a desiccator.

\section{3 | Gallic acid encapsulation and release}

Gallic acid solution $\left(2.3 \times 10^{-2} \mathrm{~mol} \mathrm{~L}^{-1}\right.$, in methanol $\left.2 \% \mathrm{v} / \mathrm{v}\right)$ was dissolved in $\mathrm{H}_{3} \mathrm{PO}_{4} / \mathrm{NaOH}$ buffer $(\mathrm{pH} 3 \pm 0.5) .{ }^{13}$ Dry composite samples (30 $\pm 3 \mathrm{mg}$ ) were immersed in $5 \mathrm{~mL}$ of gallic acid solution at $25 \pm 1^{\circ} \mathrm{C}$ and $60 \mathrm{rpm}$. The amount of phenolic acid in the solution was assessed by UV-vis spectrophotometry, until the absorbance values stabilize. The gallic acid loading was calculated based on the variation of gallic acid in the initial solution and at the equilibrium.

The gallic acid release, from composites, was performed using load dry samples. The samples (30 $\pm 3 \mathrm{mg}$ ) were immersed in $5 \mathrm{~mL}$ of synthetic sweat solution (SSS, $0.5 \mathrm{~g}$ of I-histidine monohydrochloride monohydrate, $5 \mathrm{~g}$ of sodium chloride, and $2.2 \mathrm{~g}$ of sodium dihydrogen orthophosphate dihydrate, $\mathrm{pH} 5 \pm 0.5$ ). The samples were maintained at $25 \pm 1{ }^{\circ} \mathrm{C}$, and the absorbance of the released medium was monitored until stabilization. A comparison of goodness-of-fit to the Peppas-Sahlin model was carried out by fitting the model to the experimental data. Optimal parameters were found through the software DDSolver. ${ }^{14}$

In both cases, loading and release, the absorbance was measured at the gallic acid $\lambda_{\max }\left(259 \mathrm{~nm}\right.$ for $\mathrm{pH} 3, \varepsilon 2.30 \mathrm{M} \mathrm{cm}^{-1}$ or $261 \mathrm{~nm}$ for $\mathrm{pH} 5, \varepsilon 4.27 \mathrm{M} \mathrm{cm}^{-1}$ ). The gallic acid concentration was calculated based on the calibration curve, previously determined. All the absorption measurements were recorded on a Jasco V560 spectrometer, using a 1-cm quartz cuvette.

\section{4 | Physic-chemical characterization}

Fourier transform infrared spectroscopy (FTIR-ATR) spectrums were obtained by analyzing samples ( $0.5 \pm 0.05 \mathrm{~g})$ of each composite with or without gallic acid, COT- $\beta C D-H P M C, N W-\beta C D-H P M C$, GZ- $\beta C D-$ HPMC, COT-HP $\beta C D-H P M C, N W-H P \beta C D-H P M C$, and GZ-HPBCDHPMC. The spectra were recorded between 400 and $4000 \mathrm{~cm}^{-1}$, in FTIR Shimadzu IRAffinity.

The thermal properties of the developed composites were characterized by differential scanning calorimetry (DSC) and thermogravimetry (TGA). DSC measurements were carried in liquid nitrogen atmosphere using DSC-822e instrument (Mettler Toledo). The calibration was made with indium as standard. Samples were weighed $(2.5 \pm 0.2 \mathrm{mg})$ and sealed in aluminum pans. Then they were heated from $25^{\circ} \mathrm{C}$ to $350^{\circ} \mathrm{C}$, at a scanning rate of $10^{\circ} \mathrm{C} \mathrm{min}{ }^{-1}$. Data were treated using LAB Mettler star SW 8.1 software (Mettler-Toledo International Inc, Swiss). Composite samples' thermal behavior was, also, investigated employing the simultaneous thermogravimetrydifferential scanning calorimetry (TG-DSC) technique using a TA Instruments model Hitachi STA7200. The samples (mass approx. $10 \mathrm{mg}$ ) were heated $\left(20^{\circ} \mathrm{C}\right.$ to $\left.600^{\circ} \mathrm{C}\right)$ in a standard alumina sample pan. All experiments were performed under dynamic nitrogen at a flow rate of $0.1 \mathrm{dm}^{3} \mathrm{~min}^{-1}$ using a heating rate of $10^{\circ} \mathrm{C} \mathrm{min}{ }^{-1}$ per run. Degradation onset temperature was assigned at the temperature at which $90 \%$ mass remained.

\section{5 | Mechanical properties}

Strain-to-break tensile testing was performed using the tensile film geometry on a TA Instruments Hitachi DMA7100. Samples were cut into rectangular cuboids, measured, and clamped to the DMA geometry. A controlled extension force of $5 \mathrm{~N} \mathrm{~min}^{-1}$ was applied to the sample until the sample broke or the instrument reached maximal 
extension; experiments were conducted at room temperature. At least three replicate measurements of each samples were conducted.

\section{6 | Composites biological properties assessment}

\subsection{1 | Antimicrobial properties}

The composites' antibacterial activity was tested against two bacteria: Staphylococcus aureus (ATCC 6538) and Escherichia coli (ATCC 25992). The absorption method described in JIS L 1902:2008 was used, with the following alterations. ${ }^{15}$ An inoculum was prepared in $20.0 \pm 0.1 \mathrm{~mL}$ of TSB (Tryptic Soy Broth, Merck) and incubated for a period of 18 hours at $37 \pm 1^{\circ} \mathrm{C}$ under agitation (120 rpm). Subsequently, the bacterial concentration was adjusted to $3 \times 10^{8}$ cells $\mathrm{mL}$ ${ }^{-1}$ via absorbance readings and based on a corresponding calibration curve. An aliquot of the above suspension $(400 \mu \mathrm{L})$ was added to $20 \mathrm{~mL}$ of TSB and incubated for 3.0 hours at $37 \pm 1^{\circ} \mathrm{C}$. The bacterial concentration was again measured, and $3 \times 10^{5}$ cells $\mathrm{mL}^{-1}$ were obtained using a 20-fold dilution of TSB (in distilled water). The $50 \mu \mathrm{L}$ of this inoculum was then added to each sample $(1 \pm 0.01 \mathrm{~g})$. Samples were incubated for 8 or 24 hours at $37 \pm 1^{\circ} \mathrm{C}$. Subsequently, $5 \mathrm{~mL}$ of physiological saline solution $(8.5 \mathrm{~g}$ of $\mathrm{NaCl}$ and $2.0 \mathrm{~g}$ of nonionic surfactant Tween 20 [Sigma Chemical Co] per litter) were added to the samples, which were then vortexed five times for 5 seconds. The number of living bacteria was assessed by the serial dilution plate count method. All assays were performed in triplicate and repeated three times.

\subsection{2 | Anti-inflammatory properties}

The anti-inflammatory properties of the developed composites was evaluated in vitro, using the murine macrophage (RAW 264.7) cell line, according to the method previously described by Sobral and coworkers. ${ }^{16}$ The cells were cultured in DMEM medium and incubated at $37 \pm 1^{\circ} \mathrm{C}$ under $5 \% \mathrm{CO}_{2}$, in humidified air. For each experiment, cells were detached with a cell scraper and seeded at $1.5 \times 10^{5}$ cells per well in a 96-well plate. The plate was incubated overnight to allow their attachment. The samples were kept in DMEM for 24 hours. Then the extracted solution of the samples was added to each well, and plate was incubated for 1 hour. The following step was stimulation with LPS ( $\left.1 \mu \mathrm{g} \mathrm{mL}^{-1}\right)$ for 24 hours. The effect of all tested samples in the absence of LPS was also evaluated. The cells were incubated again for 24 h. A Griess Reagent System Kit was used to nitric oxide (NO) determination, which contains sulfanilamide, N-1naphthylethylenediamine dihydrochloride (NED), and nitrite solutions. The cell culture supernatant $(100 \mathrm{~mL})$ was transferred to the plate, in duplicate, and mixed with sulfanilamide and NED solutions. The nitrite produced was determined by measuring the optical density at $540 \mathrm{~nm}$, in the microplate reader, and was compared with the standard calibration curve $\left(y=0.0063 x+0.1262, R^{2}=0.9994\right)$. The results were expressed in percentages of inhibition of $\mathrm{NO}$ production in comparison with the negative control (100\%). Dexamethasone (Sigma-Aldrich, St Louis, MO, USA was used as positive control (IC50 = $15.69 \pm 1.35 \mu \mathrm{g} / \mathrm{mL})$.
All procedures were performed in triplicate. An analysis of variance (ANOVA) was carried out to determine any significant differences between the standard conditions and the new adaptations. The data were processed with the GraphPad Prism program for Windows, version 7 .

\section{3 | RESULTS AND DISCUSSION}

Nowadays, consumers are more aware of natural products and ecofriendly procedures' benefits. Products obtained from natural sources are biocompatible and biodegradable, opposing to most synthetic products. The search for goods with high biocompatibility and reduced side-effects is paramount for the wound dressing market. ${ }^{17-20}$ Thus, we developed a composite wound dressing based on products from natural sources, cotton, cyclodextrins, and cellulose. The cotton still is a standard dressing for wound management, since it offers mechanical support and gas and water permeability. ${ }^{21}$ Cellulose, as the main component of cotton, is nontoxic, homeostatic, nonallergic, and biocompatible. $^{22}$ Cyclodextrins are biocompatibility cyclic oligosaccharides and approved by FDA. ${ }^{23}$ They are able to protect and modulate the release of a wide range of molecules. ${ }^{23}$ An antimicrobial agent, gallic acid, was also used in the present work to add the ability to prevent and control infection to the composite. Gallic acid antimicrobial activity, biocompatibility, and incorporation on a cyclodextrincellulose-based hydrogel were already proved in other works. ${ }^{13,24-26}$

\section{1 | Gallic acid loading}

All the composites were able to retain gallic acid in their structure, with similar loading profile. Gallic acid loading equilibrium was reached after 360 minutes for the composites (COT-HPMC-CD, NW-HPMC-CD, and GZ-HPMC-CD) and immediately for the nonfunctionalized textile substrates (COT, NW, and GZ). The cyclodextrin used had the same influence on the three substrates. The composites obtained with HPMC-HPBCD were able to retain more gallic acid than the ones with HPMC- $\beta C D$. These results are in accordance with the polymeric networks and composites swelling behavior. Since in previous works, it was observed that the HPMC-HPBCD composites could accommodate more water molecules than HPMC- $\beta C D^{11}$ and gallic acid had more affinity to form inclusion complexes with HP $\beta C D$, than with $\beta C D{ }^{13,27}$ Regardless the cyclodextrin used, the GZ composites showed more affinity to gallic acid (Figure 1). They retained $256 \mathrm{mg} \mathrm{GA} / \mathrm{g}$ composite (HPMC- $\beta C D$ ) and $388 \mathrm{mg} \mathrm{GA} / \mathrm{g}$ composite (HPMC-HPBCD).

The hydrogel network assembled on the cotton fibers was the manly responsible for the composite ability to retain gallic acid. The loading profile was, also, influenced by the cross-linking degree of the polymeric network, cyclodextrins available to form inclusion complex with the phenolic compound, and gallic acid affinity to all network compounds. ${ }^{11}$

\subsection{1 | Physic-chemical characterization}

Figure 2 shows the FTIR spectrum of the composites with or without gallic acid. The FTIR spectrums of the composites COT-HPMC-CD, 


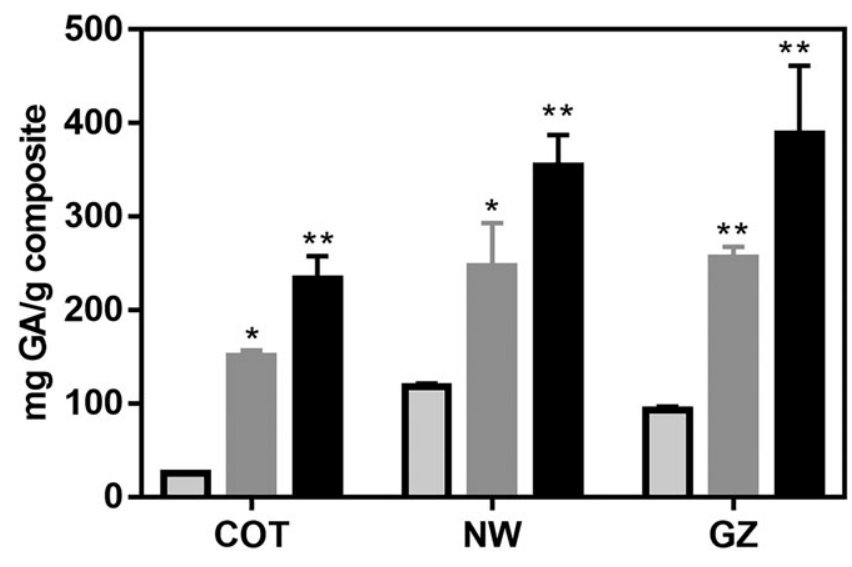

FIGURE 1 Gallic acid loading in COT, NW, or GZ (white), composites with HPMC- $\beta C D$ (grey), and composites with HPMC-HPßCD (black). The loading was performed during 24 hours, $25 \pm 1^{\circ} \mathrm{C}$ with gallic acid dissolved on the buffer $\mathrm{H}_{3} \mathrm{PO}_{4} / \mathrm{NaOH}(\mathrm{pH} 3 \pm 0.5,2 \% \mathrm{v} / \mathrm{v} \mathrm{MeOH})$. All data are expressed as mean and standard deviation $(n=3)$. Statistically different from COT/NW or GZ, ${ }^{*} P<0.001$ and ${ }^{* *} P<0.0001$

NW-HPMC-CD, and GZ-HPMC-CD were analyzed in the first part of this work. ${ }^{11}$ On gallic acid FTIR spectrum (Figure 2, black), there is a broad peak from the aromatic and carboxylic $\mathrm{O}-\mathrm{H}$ stretching at 3483 and $3256 \mathrm{~cm}^{-1}$. At $2924 \mathrm{~cm}^{-1}$ was identified the peak correspondent to hydrogens bonds stretching between the phenolic groups. The intense peaks at 1659 and $1605 \mathrm{~cm}^{-1}$ result from the conjugate acids $\mathrm{C}-\mathrm{O}$ stretching. The combination of OCC asymmetric stretching and $\mathrm{OH}$ bend is observed through to the peaks at 1425 and $1264 \mathrm{~cm}^{-1}$. The aromatic ring stretching is detected at $1432 \mathrm{~cm}$ -1 , and the $\mathrm{CO}$ stretching is displayed at $1218 \mathrm{~cm}^{-1}$. The peaks observed at $1029 \mathrm{~cm}^{-1}$ result from the out-of-plane aromatic bending. ${ }^{28,29}$ The composites with gallic acid had similar profiles to the materials without gallic acid. However, they display the appearance of two peaks at 1659 and $1605 \mathrm{~cm}^{-1}$, identified as C-O stretching from the gallic acid conjugate acids, confirming the presence of gallic acid on the composite materials.

Figure 3 (black) displays the gallic acid DSC spectrum. Since the phenolic acid is a pure substance, only an endothermic sharp peak was observed. The gallic acid did not induce any changes on the composites' thermal properties detected by DSC. All composites showed two endothermic peaks associated with the water lose (between $100^{\circ} \mathrm{C}$ and $150^{\circ} \mathrm{C}$ ) and the cyclodextrins degradations near $300^{\circ} \mathrm{C}^{11}$

Therefore, composites were subject to TGA analysis to evaluate their weight change with the temperature increase. From Figure 4 and Table 1, it is possible to observe that the presence of gallic acid induced changes on composites thermal behavior, detected by TGA. Regardless the cyclodextrin or textile substrate used, the gallic acid decreased the degradation temperature ( $\mathrm{Tg}$ ). Gallic acid maximum weight lost temperature occur near $275^{\circ} \mathrm{C}$, as consequence of it crystalline melting. ${ }^{30}$ Hence, the composites with gallic acid Tg increment confirms the presence of gallic acid on the network. Gallic acid presence was, also, proved by the weight loss. The remaining weight percentage after decomposition was superior for the composites with gallic acid. Similar effect on the thermal behavior of fibers loaded with gallic acid was described by Neo and coworkers. ${ }^{30}$ They found that gallic acid shifts the loaded fibers $\mathrm{Tg}$ to a lower temperature, when compared with the pure gallic acid as result of a change on the phenolic compound physical state. ${ }^{30}$

\section{2 | Composites' mechanical properties}

Even though hydrogels gather suitable properties for wound treatment, they lack mechanical stability, reducing their performance on the wound site. ${ }^{31}$ Considering this drawback, the mechanical stiffness of the developed composites was assessed by DMA (Table 2).

The storage moduli $\left(E^{\prime}\right)$ represents the stiffness of a viscoelastic material and is proportional to the energy stored during a loading cycle. $^{32}$ Table 2 lists the $\mathrm{E}^{\prime}$ of the controls (COT, NW, and GZ) and composites with and without gallic acid at $25 \pm 1^{\circ} \mathrm{C}$ (storage temperature) and $36 \pm 1{ }^{\circ} \mathrm{C}$ (end-use temperature). The temperature had no effect on the textile subtracts' stiffness. However, the increase of temperature reduced the stiffness of the composites. The gallic acid encapsulation, also, reduced the $E^{\prime}$ of the composites.

\section{3 | In vitro gallic acid release}

Composites ability to release gallic acid was assessed using a synthetic sweat solution, to mimic the conditions found on the skin surface. All
(A)

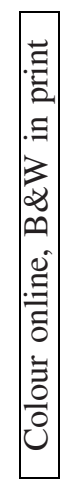

(B)

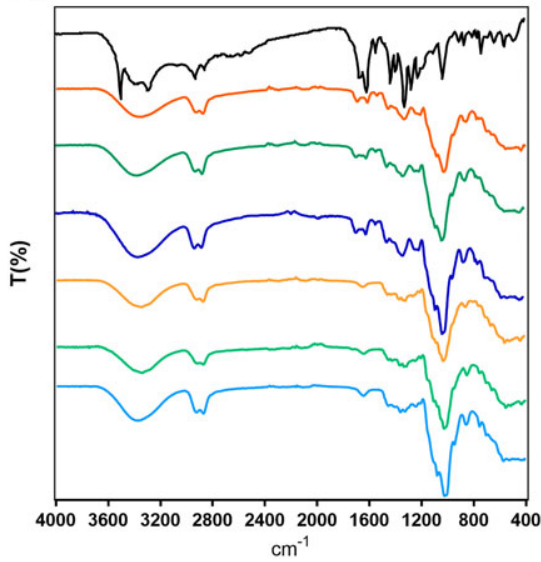

FIGURE 2 FTIR spectra gallic acid (black), COT-HPMC-CD (light blue), COT-HPMC-CD/ GA (dark blue), NW-HPMC-CD (light green), NW-HPMC-CD/GA (dark green), GZ-HPMCCD (light orange), and GZ-HPMC-CD/GA (dark orange), with (A) $\beta C D$ or (B) HPBCD [Colour figure can be viewed at wileyonlinelibrary.com] 
FIGURE 3 DSC spectra gallic acid (black), COT-HPMC-CD (light blue), COT-HPMC-CD/ GA (dark blue), NW-HPMC-CD (light green), NW-HPMC-CD/GA (dark green), GZ-HPMC$C D$ (light orange), and GZ-HPMC-CD/GA (dark orange), with (A) $\beta C D$ or (B) HP $\beta C D$ [Colour figure can be viewed at wileyonlinelibrary.com]

FIGURE 4 TGA spectra textile subtract (black; A and B, COT; C and D, NW; E and F, GZ), COT-HPMC-CD (light blue), COTHPMC-CD/GA (dark blue), NW-HPMC-CD (light green), NW-HPMC-CD/GA (dark green), GZ-HPMC-CD (light orange), and GZ-HPMC$C D / G A$ (dark orange), with (A, C, D) $\beta C D$ or (B, $D$, F) HP $\beta C D$ [Colour figure can be viewed at wileyonlinelibrary.com]
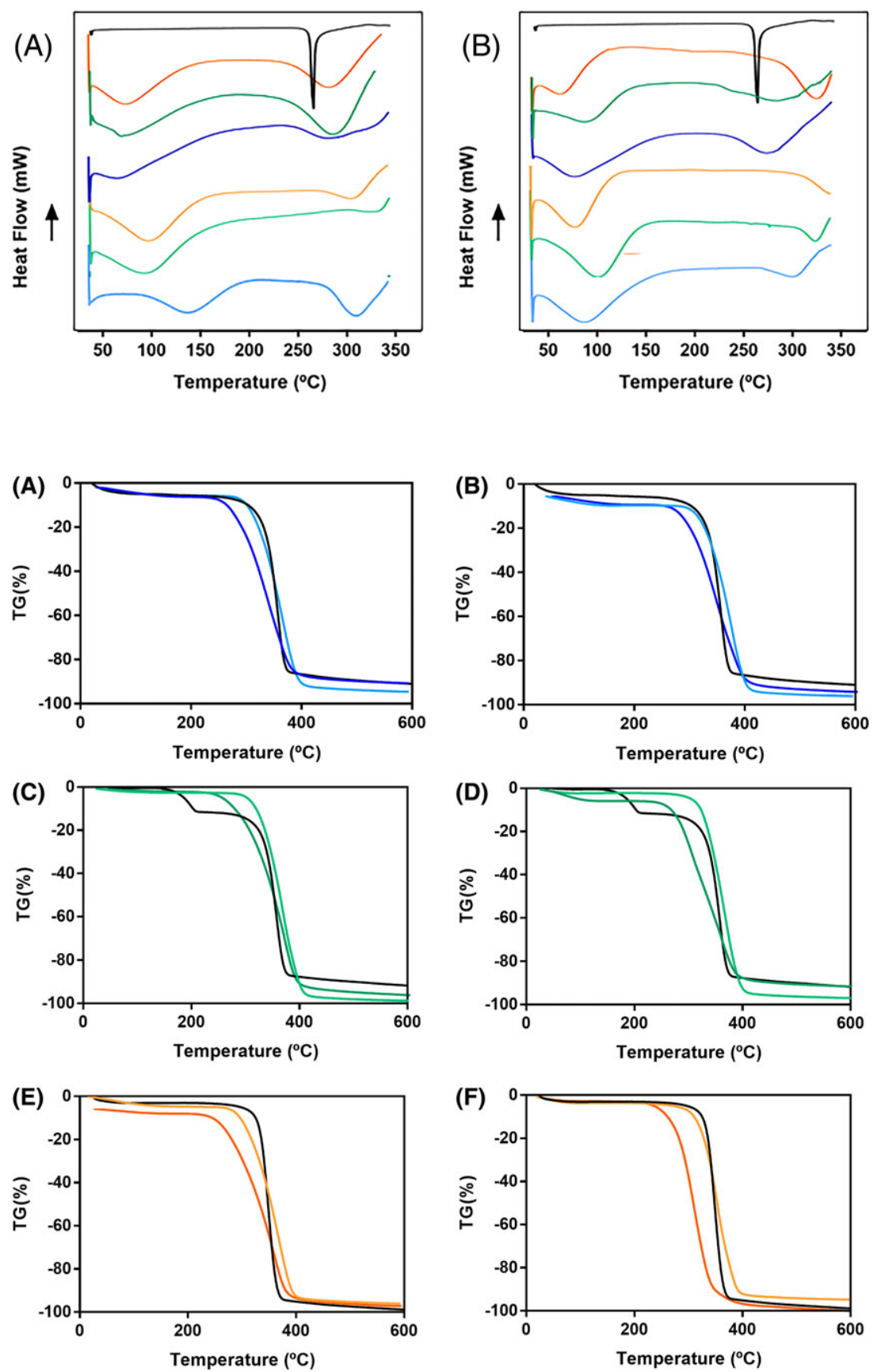

TABLE 1 TGA values of the composite materials with or without gallic acid

\begin{tabular}{|c|c|c|c|c|c|c|}
\hline & \multicolumn{2}{|l|}{ СOT } & \multicolumn{2}{|l|}{ NW } & \multicolumn{2}{|l|}{ GZ } \\
\hline & $\mathrm{Tp},{ }^{\circ} \mathrm{C}$ & G, \% & $\mathrm{Tp},{ }^{\circ} \mathrm{C}$ & $\mathrm{Tp},{ }^{\circ} \mathrm{C}$ & $\mathrm{Tp},{ }^{\circ} \mathrm{C}$ & G, $\%$ \\
\hline HPMC- $\beta C D$ & 372 & 13.26 & 376 & 10.06 & 380 & 12.81 \\
\hline HPMC-HPßCD & 376 & 13.67 & 373 & 9.31 & 361 & 12.80 \\
\hline HPMC-HPßCD/GA & 338 & 15.88 & 362 & 18.30 & 320 & 18.27 \\
\hline
\end{tabular}

composites were capable of sustaining the gallic acid release for 48 hours. It was observed a faster release during the first 360 minutes, followed by a plateau until 48 hours. The phenolic acid migration from the composite surface to the solution was responsible for the initial burst. The slower release, overserved after 6 hours, was a consequence of the inclusion complexes gallic acid-cyclodextrin dissociation. $^{24}$

The gallic acid quantity released from composites (Figure 5) was in accordance with the loading results (Figure 1). The textile substrate released almost all the gallic acid loaded (COT 71\%, NW 71\%, and 
TABLE 2 Storage moduli $\left(E^{\prime}\right)$ of the composites with and without gallic acid, at $25 \pm 1^{\circ} \mathrm{C}$ and $36 \pm 1^{\circ} \mathrm{C}$

\begin{tabular}{|c|c|c|c|c|c|c|}
\hline \multirow[b]{2}{*}{$E^{\prime}\left(10^{8} \mathrm{~Pa}\right)$} & \multicolumn{2}{|l|}{ COT } & \multicolumn{2}{|l|}{ NW } & \multicolumn{2}{|l|}{ GZ } \\
\hline & $25^{\circ} \mathrm{C}$ & $36^{\circ} \mathrm{C}$ & $25^{\circ} \mathrm{C}$ & $36^{\circ} \mathrm{C}$ & $25^{\circ} \mathrm{C}$ & $36^{\circ} \mathrm{C}$ \\
\hline Control & 0.61 & 0.66 & 0.94 & 1.11 & 0.41 & 0.56 \\
\hline HPMC- $\beta C D / G A$ & 0.21 & 0.12 & 2.17 & 1.23 & 5.96 & 2.70 \\
\hline HPMC-HP $\beta C D$ & 2.41 & 1.19 & 1.80 & 1.50 & 2.20 & 1.45 \\
\hline
\end{tabular}

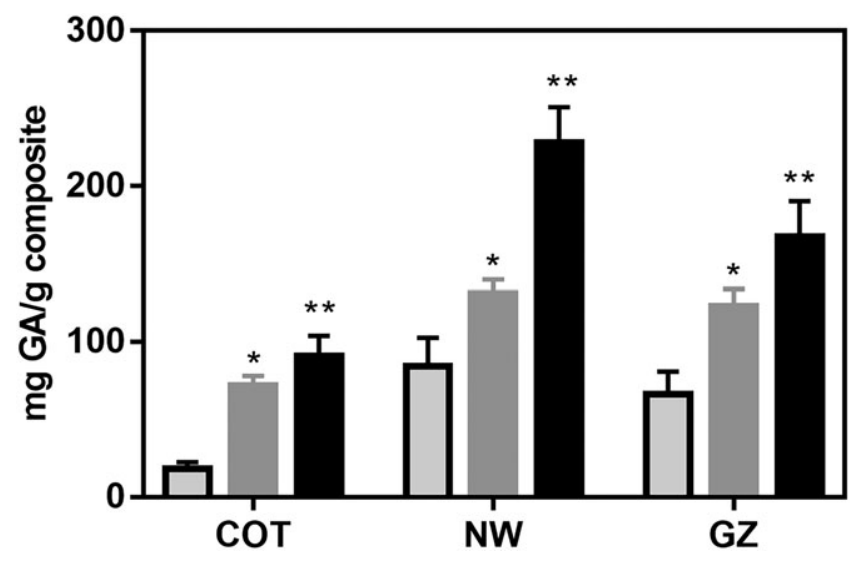

FIGURE 5 Gallic acid release from COT, NW, or GZ (white), composites with HPMC- $\beta C D$ (grey), and composites with HPMC$\mathrm{HP} \beta C D$ (black). It was performed during 48 hours, $37 \pm 1^{\circ} \mathrm{C}$ within synthetic sweat solution $(\mathrm{pH} 5 \pm 0.1)$. All data are expressed as mean and standard deviation $(n=3)$. Statistically different from COT/NW or GZ, ${ }^{*} P<0.001$ and ${ }^{* *} P<0.0001$

GZ $72 \% w / w)$. The composites functionalized with HPMC- $\beta C D$ or HPMC-HP $\beta C D$ released $39 \%$ and $64 \%(w / w)$ of the gallic acid retained on the network.

Composites drug delivery capacity is highly dependent on the hydrogel network swelling and release properties. Thus, their drug delivery capacity is set by the following process: solvent transport into the polymeric matrix, polymer swelling, solute diffusion, and erosion/relaxation of the swollen polymer. ${ }^{33-35}$ Furthermore, previous studies had proven that the use of cyclodextrins on the polymeric hydrogel benefits their drug delivery properties. ${ }^{33,36,37}$

In this case, the inclusion complex strength, between the cyclodextrins and gallic acid, had a major influence on the drug delivery capacity of the composites. The inclusion complexes HPBCD-gallic acid are more stable than the ones obtained with $\beta C D .{ }^{13,24}$ Therefore, despite HPMC-HPBCD composites accommodating more gallic acid, the amount released was similar to HPMC- $\beta C D$ composites.
For a more comprehensive characterization of the release profiles, the data were analyzed by fitting to Peppas-Sahlin model (Equation 1), since it have been successfully applied to HPMC and cyclodextrin based hydrogel drug delivery systems. ${ }^{33-35,38}$ This release kinetics model considers the diffusional and relaxational mechanism associated with the anomalous drug released process of hydrogels. ${ }^{39}$ Considering the right side of Equation 1, the first term calculates the molecular diffusion of the drug as consequence of the chemical potential gradient, Fickian contribution (F). The second term represents the Case II relaxation contribution $(R)$, set by the stress and state-transition of swelling-controlled drug release. ${ }^{34,40}$

$$
\frac{M_{t}}{M_{\infty}}=k_{D} t^{m}+k_{R} t^{2 m}
$$

where $M_{t}$ and $M_{\infty}$ are the absolute cumulative amount of drug released at time ( $t$, minute) and infinite time and $k_{D}$ (diffusional constant), $\mathrm{k}_{\mathrm{R}}$, and $\mathrm{m}$ are constants. ${ }^{41}$

A good fitting was observed between the experimental data and the Peppas-Sahlin model, since the $r^{2}$ values were superior to 0.90 for all the composites (Table 3). Moreover, $k_{D}$ values were always superior to $k_{R}$, meaning that the drug release mechanics of the composites was control by Fickian diffusion. ${ }^{42}$ The functionalization with hydrogels significantly influence the release profiles of the textiles substrates, improving it. The diffusional constants obtained were superior for the composites, comparative with the control substrates, regardless the cyclodextrins used. The predominance of Fickian diffusion as drug delivery mechanism on cyclodextrin-based hydrogels was also described in several works. ${ }^{33,43,44}$

The same behavior was, also, observed on composites obtained by the conjugation of hydrogel networks and textile substrates. For instance, Cirillo and coworkers ${ }^{45}$ developed a cotton-gauze-hydrogel composite electroresponsive drug delivery system to be used as wound dressing. By fitting the experimental data to the Peppas-Sahlin model, they conclude that the release rate was faster when high voltages were applied and Fickian diffusion was the prevalent mechanism of drug delivery. ${ }^{45}$

TABLE 3 Composites' kinetics release parameters using Peppas and Sahlin model (Equation 1)

\begin{tabular}{|c|c|c|c|c|c|c|c|c|c|}
\hline & \multicolumn{3}{|l|}{ Control } & \multicolumn{3}{|l|}{ HPMC- $\beta C D$} & \multicolumn{3}{|c|}{ HPMC-HPßCD } \\
\hline & $r^{2}$ & $\mathrm{k}_{\mathrm{D}}$ & $k_{R}$ & $r^{2}$ & $k_{D}$ & $k_{R}$ & $r^{2}$ & $k_{D}$ & $k_{R}$ \\
\hline COT & $0.89 \pm 0.07$ & $10.22 \pm 0.06$ & $-1.53 \pm 0.05$ & $0.94 \pm 0.05$ & $29.25 \pm 0.73$ & $-2.85 \pm 0.09$ & $0.95 \pm 0.03$ & $16.21 \pm 0.27$ & $-0.66 \pm 0.08$ \\
\hline GZ & $0.96 \pm 0.03$ & $41.15 \pm 0.03$ & $-6.29 \pm 0.43$ & $0.91 \pm 0.03$ & $42.24 \pm 0.39$ & $-3.50 \pm 0.07$ & $0.90 \pm 0.03$ & $40.49 \pm 0.48$ & $-2.40 \pm 0.58$ \\
\hline
\end{tabular}




\section{4 | Composites biological properties}

\subsubsection{Antimicrobial capacity}

The presence of microorganism on the wound bed may delay the healing process, giving rise to chronic wounds. Gallic acid is a simple phenolic acid with good applicability as antibacterial agent against bacteria, commonly isolated from infected wounds. ${ }^{46}$ It was, already used, with success to add antimicrobial properties to hydrogels networks. ${ }^{24,28,47}$ Thus, the antimicrobial activity of the developed composites was investigated (Figure 6). The textiles substrates (COT, $N W$, or GZ), the functionalized substrates with HPMC- $\beta C D$, or HPMC-HPBCD prevented the bacteria growth. Otherwise, the composite materials loaded with gallic acid destroyed all bacteria, independently the contact time. According to the results obtained, it was verified that the gallic acid's antibacterial activity was preserved after incorporation within the composite material.

Even though natural antimicrobial agents have been described as a viable alternative to antibiotics on the chronic wound treatment, just a few paper are available reporting the use of antimicrobial agents to functionalize cotton-hydrogel composites. Nevertheless, they support the above results regarding the maintenance of the natural agents' antimicrobial activity after their encapsulation by textile-hydrogel composites. ${ }^{48,49}$ For instance, $\mathrm{Xu}$ and coworkers were able to incorporate a berberine nanosuspension in a poly( $\mathrm{N}$-isopropylacrylamide)/alginate copolymer hydrogel-grafted fabrics. Based on their results, the developed composite was able to sustain the release of berberine, and it kept their biological properties (antimicrobial effect, promotion of granulation and capillary formation, wound closure, moisture regulation, and hemostasis). ${ }^{48}$ Similar results were described using a cotton fabric modified with a chitosan-poly( $N$-isopropylacrylamide) interpenetrating polymer network hydrogel. ${ }^{49}$ The chitosan antimicrobial activity was present on the cotton modified fabric, as well as the thermosensitive behavior of the hydrogel network. ${ }^{49}$

\subsection{2 | Anti-inflammatory properties}

Chronic wounds result from a breakdown on the healing process, caused by prolonged inflammation stage. Infection has been described as the major cause of chronic wounds, specially the presence of biofilms. The persistent of infection stimulate the constant influx of immune cells, extending the proinflammatory cytokine cascade and rise the proteases concentration on the wound bed. The inhibition of protease fails, leading to the destruction of the extracellular matrix and growth factors, as well as their receptors. This prevents the wound from moving forward to the proliferative phase and attracts more inflammatory cells, intensifying the inflammatory cycle. ${ }^{3,50-52}$

The production reactive nitrogen species is a consequence of the inducible nitric oxide synthase (iNOS) activity, an inflammatory mediator. NO (nitric oxide) has been described as an important mediator of acute and chronic inflammation. ${ }^{53}$ Thus, NO has been used as parameter to assess in vitro the anti-inflammatory capacity of molecules and materials. $^{54}$

Therefore, the anti-inflammatory properties of the developed composites were assessed by the quantification of (NO) production inhibition. The loaded composites (HPMC- $\beta C D / G A$ and HPMC$\mathrm{HP} \beta C D / G A)$, regardless the subtracted used, were able to prevent $60 \%$ of the NO production by the cells RAW 264.7 (Figure 7). Otherwise, the controls and composites without GA, only, prevent between $10 \%$ and $30 \%$ of the NO production.

Gallic acid, besides its antimicrobial activity, has been described as a strong anti-inflammatory agent. ${ }^{23,55}$ A direct relation between the concentration of gallic acid and the inhibition of NO production in LPS/IFN- $\gamma$-activated macrophages was, also, demonstrated by Wang and coworkers. ${ }^{56}$ Accordingly, gallic acid was able to migrate from the cyclodextrins cavity and hydrogel network to the medium, without losing biological properties, based on the obtained results.

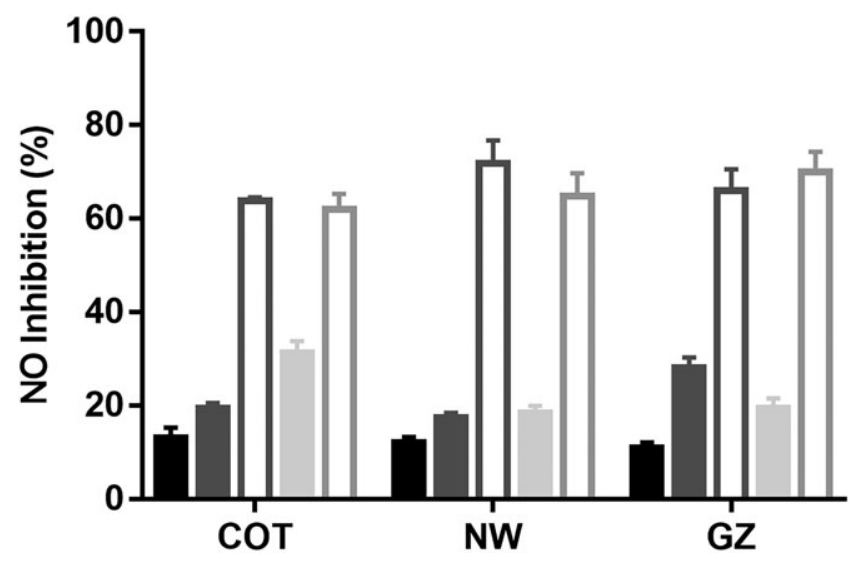

FIGURE 7 Composites' anti-inflammatory activity by quantification of the NO (nitric oxide) inhibition production percentage. COT, NW, or GZ (black), composites functionalized with HPMC- $\beta C D$ (fill dark grey), HPMC- $\beta C D / G A$ (no fill dark grey), and composites with HPMC$\mathrm{HPBCD}$ (fill light grey) and HPMC-HPBCD/GA (no fill light grey)
FIGURE 6 Quantitative analysis of antibacterial activity of the gallic acid loaded composites by direct contact, for 8 or 24 hours, against (A) Staphylococcus aureus and (B) Escherichia coli, $5 \times 10^{5}$ cells $\mathrm{mL}^{-1}$. $\square$ COT- $\beta C D, \square N W-\beta C D, \square G Z-\beta C D, \square C O T-$ $\mathrm{HP} \beta C D, \square N W-H P \beta C D, \square G Z-H P \beta C D$; $\square \mathrm{COT}-\beta C D / G A, \square N W-\beta C D / G A, \square G Z-\beta C D /$ $\mathrm{GA}, \square \mathrm{COT}-\mathrm{HP} \beta C D / G A, \square N W-H P \beta C D / G A$, and $\square \mathrm{GZ}-\mathrm{HP} \beta \mathrm{CD} / \mathrm{GA}$ [Colour figure can be viewed at wileyonlinelibrary.com]
(A)

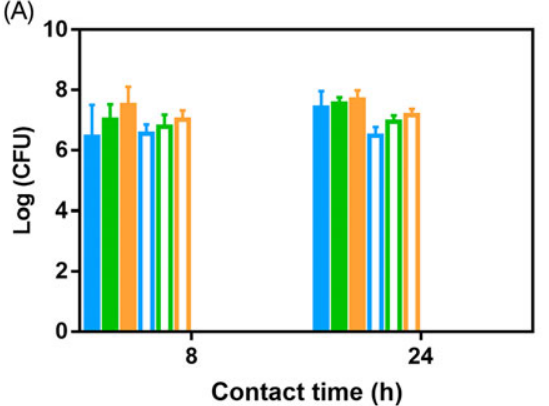

(B)

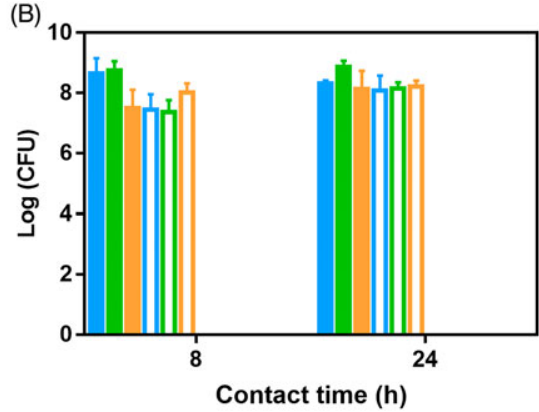




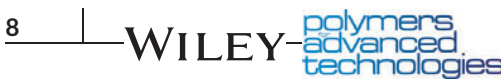

\section{4 | CONCLUSIONS}

In a previous work, the synthesis optimization and physicochemical characterization of composite wound dressings obtained by the cross-linking between cotton textile substrates and cyclodextrincellulose based hydrogels were performed. It was proved that the functionalization of the textile substrates improved their applicability as wound dressing.

Regarding the present work, encapsulation of antimicrobial gallic acid by the developed materials gave rise to a composite wound dressing with enhanced biological properties. Gallic acid was successfully loaded into the composite materials, and its presence was proven by FTIR and TGA composite profiles. The phenolic acid release was improved by the presence of cyclodextrins and was mainly driven by Fickian diffusion. The antimicrobial and anti-inflammatory properties of gallic acid were not compromised after its incorporation on the composites network.

Thus, it is possible to synthetize composite wound dressings using natural compounds and eco-friendly procedures and transfer the antimicrobial and anti-inflammatory properties gallic acid to it. This work presents a valuable route towards the functionalization of cotton improving its application as wound dressing.

\section{ACKNOWLEDGEMENTS}

This article is a result of the project TSSiPRO-NORTE-01-0145FEDER-000015-supported by the regional operational program NORTE 2020, under the PORTUGAL 2020 Partnership Agreement, through the European Regional Development Fund. The authors, also, acknowledge the Portuguese Foundation for Science and Technology (FCT) funding from the project UID/CTM/00264/2013 and UID/AGR/00690/2013 and FEDER funds through the COMPETE 2020-Programa Operacional Competitividade e Internacionalização (POCI) with the reference project POCI-01-0145-FEDER-007136.

\section{ORCID}

Eva Pinho (i) https://orcid.org/0000-0002-0321-9089

Ricardo C. Calhelha (D) https://orcid.org/0000-0002-6801-4578

Isabel C.F.R. Ferreira (i) https://orcid.org/0000-0003-4910-4882

Graça Soares (D) https://orcid.org/0000-0003-0104-6521

\section{REFERENCES}

1. Dissemond J, Eming SA, Goerge T, et al. Modern wound care-practical aspects of non-interventional topical treatment of patients with chronic wounds. JDDG - J Ger Soc Dermatology. 2014;12(7):541-555. https://doi.org/10.1111/ddg.12351

2. Dhivya S, Padma VV, Santhini E. Wound dressings-a review. Biomedicine. 2015;5(4):22. https://doi.org/10.7603/s40681-015-0022-9

3. Järbrink K, Ni G, Sönnergren $H$, et al. The humanistic and economic burden of chronic wounds: a protocol for a systematic review. Syst Rev. 2017;6(1):1-7. https://doi.org/10.1186/s13643-016-0400-8

4. Lipsky BA, Hoey C. Topical antimicrobial therapy for treating chronic wounds. Clin Infect Dis. 2009;49(10):1541-1549. https://doi.org/ 10.1086/644732

5. Price LB, Liu CM, Melendez JH, et al. Community analysis of chronic wound bacteria using $16 \mathrm{~S}$ rRNA gene-based pyrosequencing: impact of diabetes and antibiotics on chronic wound microbiota. PLoS One. 2009;4(7):e6462. https://doi.org/10.1371/journal.pone.0006462
6. Gethin G. The significance of surface $\mathrm{pH}$ in chronic wounds. 2007;3(3):52-55.

7. Vashist AA, Vashist AA, Gupta YK, Ahmad S. Recent advances in hydrogel based drug delivery systems for the human body. J Mater Chem B. 2014;2(2):147-166. https://doi.org/10.1039/C3TB21016B

8. Dryden MS. Skin and soft tissue infection: microbiology and epidemiology. Int J Antimicrob Agents. 2009;34(SUPPL. 1):S2-S7. https://doi.org/ 10.1016/S0924-8579(09)70541-2

9. Rieger KA, Birch NP, Schiffman JD. Designing electrospun nanofiber mats to promote wound healing-a review. J Mater Chem B. 2013;1(36):4531. https://doi.org/10.1039/c3tb20795a

10. Pinho E, Henriques M, Soares G. Caffeic acid loading wound dressing: physicochemical and biological characterization. Ther Deliv. 2014;5(10):1063-1075. https://doi.org/10.4155/tde.14.77

11. Pinho E, Soares G. Cotton-hydrogel composite for improved wound healing: synthesize optimization and physicochemical characterization -part 1. Polym Adv Technol. 2018;(July):1-11. https://doi.org/ 10.1002/pat.4432;29(12):3114-3124.

12. Pinho E, Soares G. Functionalization of cotton cellulose for improved wound healing. J Mater Chem B. 2018;6(13):1887-1898. https://doi. org/10.1039/C8TB00052B.

13. Pinho E, Soares G, Henriques M. Cyclodextrin modulation of gallic acid in vitro antibacterial activity. J Incl Phenom Macrocycl Chem. 2015;81(1):205-214. https://doi.org/10.1007/s10847-014-0449-8

14. Zhang Y, Huo M, Zhou J, et al. DDSolver: an add-in program for modeling and comparison of drug dissolution profiles. AAPS J. 2010;12(3):263-271. https://doi.org/10.1208/s12248-010-9185-1

15. Pinho E, Soares G, Henriques M, Grootveld M. Antibacterial activity of textiles for wound treatment. AATCC J Res. 2008(5):0-6. https://doi. org/10.14504/ajr.2.5.1.

16. Sobral F, Sampaio A, Falcão S, et al. Chemical characterization, antioxidant, anti-inflammatory and cytotoxic properties of bee venom collected in Northeast Portugal. Food Chem Toxicol. 2016;94:172-177. https://doi.org/10.1016/j.fct.2016.06.008

17. Fonder MAMA, Lazarus GSGS, Cowan DADA, Aronson-Cook B, Kohli ARAR, Mamelak AJAJ. Treating the chronic wound: a practical approach to the care of nonhealing wounds and wound care dressings. J Am Acad Dermatol. 2008;58(2):185-206. https://doi.org/10.1016/j. jaad.2007.08.048

18. Sai KP, Babu M. Collagen based dressings-a review. Burns. 2000;26(1):54-62. https://doi.org/10.1016/S0305-4179(99)00103-5

19. Kujath P, Michelsen A, Article R. Wounds-from physiology to wound dressing. Dtsch Arztebl Int. 2008;105(13):239-248. https://doi.org/ 10.3238/arztebl.2008.0239

20. Boateng JS, Matthews KH, Stevens HNE, Eccleston GM. Wound healing dressings and drug delivery systems: a review. J Pharm Sci. 2008;97(8):2892-2923. https://doi.org/10.1002/.jps

21. Pedrosa M, Mouro C, Nogueira F, Vaz J, Gouveia I. Comparison of the antibacterial activity of modified-cotton with magainin I and LL-37 with potential as wound-dressings. J Appl Polym Sci. 2014;131(21):1-8. https://doi.org/10.1002/app.40997

22. Herrmann I, Supriyanto E, Jaganathan SK, Manikandan A. Advanced nanofibrous textile-based dressing material for treating chronic wounds. Bull Mater Sci. 2018;41(1):18. https://doi.org/10.1007/ s12034-017-1543-5

23. Pinho E, Grootveld M, Soares G, Henriques M. Cyclodextrins as encapsulation agents for plant bioactive compounds. Carbohydr Polym. 2014;101(1):121-135. https://doi.org/10.1016/j.carbpol.2013.08.078

24. Pinho E, Henriques M, Soares G. Cyclodextrin/cellulose hydrogel with gallic acid to prevent wound infection. Cellul. 2014;21(6):4519-4530 https://doi.org/10.1007/s10570-014-0439-4

25. Guimarães R, Barreira JCM, Barros L, Carvalho AM, Ferreira ICFR. Effects of oral dosage form and storage period on the antioxidant properties of four species used in traditional herbal medicine. Phytother Res. 2010;(June). https://doi.org/10.1002/ptr.3284;25(4):484-492. 
26. Fang Z, Bhandari B. Encapsulation of polyphenols-a review. Trends Food Sci Technol. 2010;21(10):510-523. https://doi.org/10.1016/j. tifs.2010.08.003

27. Aytac Z, Ipek S, Durgun E, Uyar T. Encapsulation of gallic $\mathrm{acid} /$ cyclodextrin inclusion complex in electrospun polylactic acid nano fibers: release behavior and antioxidant activity of gallic acid. Mater Sci Eng C. 2016;63:231-239. https://doi.org/10.1016/j.msec.2016.02.063

28. Yu SH, Mi FL, Pang JC, et al. Preparation and characterization of radical and $\mathrm{pH}$-responsive chitosan-gallic acid conjugate drug carriers. Carbohydr Polym. 2011;84(2):794-802. https://doi.org/10.1016/j. carbpol.2010.04.035

29. Bhattacharyya S, Ahammed SM, Saha BP, Mukherjee PK. The gallic acid-phospholipid complex improved the antioxidant potential of gallic acid by enhancing its bioavailability. AAPS PharmSciTech. 2013;14(3):1025-1033. https://doi.org/10.1208/s12249-013-9991-8

30. Neo YP, Ray S, Jin J, et al. Encapsulation of food grade antioxidant in natural biopolymer by electrospinning technique: A physicochemical study based on zein-gallic acid system. Encapsulation of food grade antioxidant in natural biopolymer by electrospinning technique: $A$ physicochemical study based on zein-gallic acid system. 2013;136(2): 1013-1021. https://doi.org/10.1016/j.foodchem.2012.09.010

31. Jang J, Lee J, Seol YJ, Jeong YH, Cho DW. Improving mechanical properties of alginate hydrogel by reinforcement with ethanol treated polycaprolactone nanofibers. Compos Part B Eng. 2013;45(1):1216-1221. https://doi.org/10.1016/j.compositesb.2012. 09.059

32. Enrica T. Hydrogels: Biological Properties and Applications.; 2009. http:// books.google.com/books?id=8C2r5o5gAYcC\&pgis=1.

33. Machín R, Isasi JR, Vélaz I. Hydrogel matrices containing single and mixed natural cyclodextrins. Mechanisms of drug release. Eur Polym J. 2013;49(12):3912-3920. https://doi.org/10.1016/j.eurpolymj.2013. 08.020

34. Siepmann J, Peppas NA. Modeling of drug release from delivery systems based on hydroxypropyl methylcellulose (HPMC). Adv Drug Deliv Rev. 2001;48(2-3):139-157. https://doi.org/10.1016/S0169409X(01)00112-0

35. Lin CC, Metters AT. Hydrogels in controlled release formulations: network design and mathematical modeling. Adv Drug Deliv Rev. 2006;58(12-13):1379-1408. https://doi.org/10.1016/j.addr.2006.09. 004

36. Bibby DC, Davies NM, Tucker IG. Mechanisms by which cyclodextrins modify drug release from polymeric drug delivery systems. Int J Pharm. 2000;197(1-2):1-11. https://doi.org/10.1016/S0378-5173(00)00335-5

37. Li J. Self-assembled supramolecular hydrogels based on polymercyclodextrin inclusion complexes for drug delivery. NPG Asia Mater. 2010;2(3):112-118. https://doi.org/10.1038/asiamat.2010.84

38. Ghosal K, Chandra A, Rajabalaya R, Chakraborty S, Nanda A. Mathematical modeling of drug release profiles for modified hydrophobic HPMC based gels. Pharmazie. 2012;67(2):147-155. https://doi.org/ 10.1691/ph.2012.1014

39. Siepmann J, Siepmann F. Mathematical modeling of drug delivery. Int J Pharm. 2008;364(2):328-343. https://doi.org/10.1016/j.jpharm.2008. 09.004

40. Bruschi ML. Mathematical models of drug release. In: Strategies to Modify the Drug Release from Pharmaceutical Systems. Elsevier; 2015:63-86 https://doi.org/10.1016/B978-0-08-100092-2.00005-9.

41. Peppas NA, Sahlin JJ. A simple equation for the description of solute release. III. Coupling of diffusion and relaxation. Int J Pharm. 1989;57(2):169-172. https://doi.org/10.1016/0378-5173(89)90306-2

42. Curcio M, Gianfranco Spizzirri U, lemma F, et al. Grafted thermoresponsive gelatin microspheres as delivery systems in triggered drug release. Eur J Pharm Biopharm. 2010;76(1):48-55. https://doi.org/ 10.1016/j.ejpb.2010.05.008
43. Larrañeta E, Martínez-Ohárriz C, Vélaz I, Zornoza A, Machín R, Isasi JR. In vitro release from reverse poloxamine/a-cyclodextrin matrices: modelling and comparison of dissolution profiles. J Pharm Sci. 2014;103(1):197-206. https://doi.org/10.1002/jps.23774

44. Das S, Subuddhi U. Cyclodextrin mediated controlled release of naproxen from $\mathrm{pH}$-sensitive chitosan/poly(vinyl alcohol) hydrogels for colon targeted delivery. Ind Eng Chem Res. 2013;52(39):14192-14200. https://doi.org/10.1021/ie402121f

45. Cirillo G, Spizzirri UG, Curcio M, et al. Cotton gauze-hydrogel composites: valuable tools for electrically modulated drug delivery. Int J Polym Mater Polym Biomater. 2016;65(9):442-450. https://doi.org/10.1080/ 00914037.2015 .1129956

46. Pinho E, Ferreira ICFR, Barros L, Carvalho AM, Soares G, Henriques M. Antibacterial potential of northeastern Portugal wild plant extracts and respective phenolic compounds. Biomed Res Int. 2014;2014. https:// doi.org/10.1155/2014/814590:1-8.

47. da Rosa CG, Borges CD, Zambiazi RC, et al. Microencapsulation of gallic acid in chitosan, $\beta$-cyclodextrin and xanthan. Ind Crop Prod. 2013;46:138-146. https://doi.org/10.1016/j.indcrop.2012.12.053

48. Xu H, Yuan X-DD, De SB, et al. Development of poly $(\mathrm{N}$ isopropylacrylamide)/alginate copolymer hydrogel-grafted fabrics embedding of berberine nanosuspension for the infected wound treatment. J Biomater Appl. 2014;28(9):1376-1385. https://doi.org/ 10.1177/0885328213509503

49. Wang B, Wu X, Li J, et al. Thermosensitive behavior and antibacterial activity of cotton fabric modified with a chitosan-poly $(\mathrm{N}$ isopropylacrylamide) interpenetrating polymer network hydrogel. Polymers (Basel). 2016;8(12):110. https://doi.org/10.3390/polym8040110

50. Guo S, Dipietro L a. Factors affecting wound healing. J Dent Res. 2010;89(3):219-229. https://doi.org/10.1177/0022034509359125

51. Kirketerp-Møller K, Zulkowski K, James G. Chronic wound colonization, infection, and biofilms. In: Biofilm Infections. New York, NY: Springer New York; 2011:11-24 https://doi.org/10.1007/978-14419-6084-9_2.

52. Sarheed O, Ahmed A, Shouqair D, Boateng J. Antimicrobial dressings for improving wound healing. In: Alexandrescu VA, ed. Wound Healing-New Insights into Ancient Challenges. InTech; 2016 https:// doi.org/10.5772/63961.

53. Kassim M, Achoui M, Mustafa MR, Mohd MA, Yusoff KM. Ellagic acid, phenolic acids, and flavonoids in Malaysian honey extracts demonstrate in vitro anti-inflammatory activity. Nutr Res. 2010;30(9):650-659. https://doi.org/10.1016/j.nutres.2010.08.008

54. Taofiq O, Calhelha RC, Heleno S, et al. The contribution of phenolic acids to the anti-inflammatory activity of mushrooms: screening in phenolic extracts, individual parent molecules and synthesized glucuronated and methylated derivatives. Food Res Int. 2015;76(Pt 3):821-827. https://doi.org/10.1016/j.foodres.2015.07.044.

55. Chuysinuan P, Chimnoi N, Techasakul S, Supaphol P. Gallic acid-loaded electrospun poly(L-lactic acid) fiber mats and their release characteristic. Macromol Chem Phys. 2009;210(10):814-822. https://doi.org/ 10.1002/macp. 200800614

56. Wang J, Mazza G. Inhibitory effects of anthocyanins and other phenolic compounds on nitric oxide production in LPS/IFN-gamma-activated RAW 264.7 macrophages. J Agric Food Chem. 2002;50(4):850-857. https://doi.org/10.1021/jf010976a

How to cite this article: Pinho E, Calhelha RC, Ferreira ICFR, Soares G. Cotton-hydrogel composite for improved wound healing: Antimicrobial activity and anti-inflammatory evaluation-Part 2. Polym Adv Technol. 2018;1-9. https://doi.org/ 10.1002/pat.4519 